Supplement of Biogeosciences, 15, 6747-6759, 2018

https://doi.org/10.5194/bg-15-6747-2018-supplement

(C) Author(s) 2018. This work is distributed under

the Creative Commons Attribution 4.0 License.

(c) (1)

Supplement of

\title{
The effect of the 2013-2016 high temperature anomaly in the subarctic Northeast Pacific (the "Blob") on net community production
}

Bo Yang et al.

Correspondence to: Bo Yang (by3jr@virginia.edu)

The copyright of individual parts of the supplement might differ from the CC BY 4.0 License. 


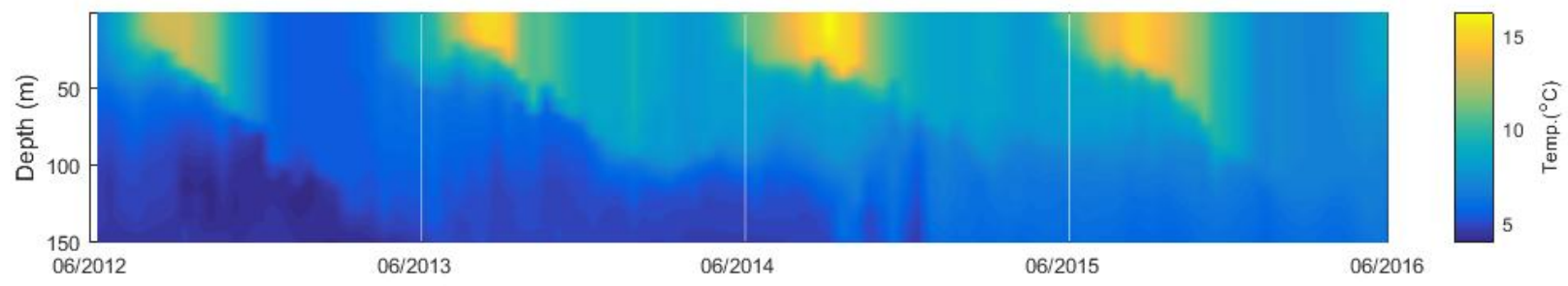

Figure S1 Upper temperature evolution measured by the SOS-Argo float at OSP, which shows the continuity of water mass during the study period (2012-2016).

Table S1 Confidence intervals for oxygen measurements and the gas exchange mass transfer coefficients used in the Monte Carlo estimate for ANCP uncertainty from the oxygen mass balance model (see also Yang et al., 2017). We considered the four most serious uncertainties (column 1) to be the degree of oxygen supersaturation $\Delta\left[\mathrm{O}_{2}\right]$; gas exchange mass transfer coefficients for: air-sea diffusive exchange, $\mathrm{k}_{\mathrm{s}}$; small bubble collapse, $\mathrm{k}_{\mathrm{c}}$; large bubble exchange $\mathrm{k}_{\mathrm{p}}$; and the eddy diffusion coefficient at the base of winter mixed layer, $\mathrm{K}_{\mathrm{z}}$.

\section{Parameter Confidence intervals (\%)}

\begin{tabular}{cc}
\hline$\Delta\left[\mathrm{O}_{2}\right]$ & \pm 0.1 \\
$\mathrm{k}_{\mathrm{s}}$ & \pm 10 \\
$\mathrm{k}_{\mathrm{c}} \& \mathrm{k}_{\mathrm{p}}$ & \pm 25 \\
$\mathrm{~K}_{\mathrm{z}}$ & \pm 50 \\
\hline
\end{tabular}

\section{Text S1 Example of residence time calculation for oxygen and DIC tracers}

Residence time $(\tau)$ with respect to gas exchange can be calculated as the examples shown by Emerson and Hedges, 2008. Initial conditions for these calculations are: $\mathrm{t}=20^{\circ} \mathrm{C}, \mathrm{TA}=2300 \mu$ mol kg${ }^{-1}, \mathrm{DIC}=2000 \mu \mathrm{mol} \mathrm{kg}{ }^{-1},\left[\mathrm{CO}_{2}\right]=11.3 \mu \mathrm{mol} \mathrm{kg}^{-1}$, Revelle Factor $\mathrm{R}=9.6$. For $\mathrm{O}_{2}$, since its solubility is very low, we can use a one-way gas exchange flux in Equation 1: 


$$
\tau=\frac{\mathrm{h} \cdot[\mathrm{C}]}{\mathrm{F}_{\text {air-water }}}=\frac{\mathrm{h} \cdot[\mathrm{C}]}{\mathrm{G} \cdot[\mathrm{C}]}=\frac{\mathrm{h}}{\mathrm{G}}
$$

Where $[\mathrm{C}]$ is the gas concentration, $\mathrm{h}$ is the mixed layer depth, $\mathrm{F}_{\text {air-water }}$ is the one-way gas change flux, and $\mathrm{G}$ is the gas exchange mass transfer coefficient.

With the mean gas exchange mass transfer coefficient of $5 \mathrm{~m} \mathrm{~d}^{-1}$ and a mixed layer depth of 100 $\mathrm{m}$, the residence time for $\mathrm{O}_{2}$ is $20 \mathrm{~d}$.

Due to the carbonate system reactions, the true reservoir size for $\mathrm{CO}_{2}$ is larger than its concentration, $\left[\mathrm{CO}_{2}\right]$. The ratio of the DIC reservoir that exchange $\mathrm{C}$ with the $\mathrm{CO}_{2}$ reservoir is $\frac{\Delta \mathrm{DIC}}{\Delta \mathrm{CO}_{2}}$. Therefore the residence time for $\mathrm{CO}_{2}$ can be calculated with Equation 2:

$$
\tau=\frac{\mathrm{h} \cdot\left[\mathrm{CO}_{2}\right]}{\mathrm{G} \cdot\left[\mathrm{CO}_{2}\right]} \times \frac{\Delta \mathrm{DIC}}{\Delta \mathrm{CO}_{2}}=\frac{\mathrm{h}}{\mathrm{G}}\left(\frac{\mathrm{DIC}}{\mathrm{R}\left[\mathrm{CO}_{2}\right]}\right)
$$

With the DIC, $\mathrm{R}$, and $\left[\mathrm{CO}_{2}\right]$ values provided above, and the $\mathrm{h} / \mathrm{G}$ value from Equation 1 , the residence time for $\mathrm{CO}_{2}$ is $368 \mathrm{~d}$.

\section{Text S2 Analysis of other environmental parameters that may cause ANCP variation}

(1) Shortwave radiation

Unfortunately there was no PAR sensor on the mooring (https://www.pmel.noaa.gov/ocs/sensors). On the other hand, it does have sensors measuring shortwave radiation, and the result (Figure S2, from https://www.pmel.noaa.gov/ocs/data/fluxdisdel/) doesn't show significant changes in shortwave radiation during those four years.

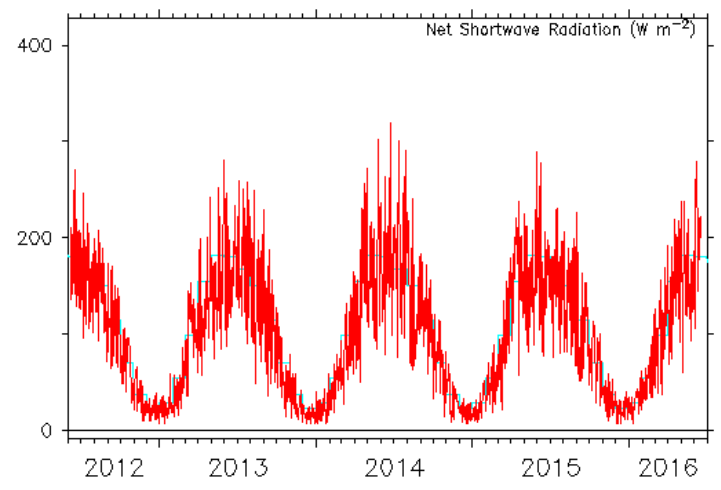


Figure S2 Net shortwave radiation data from Ocean Station Papa surface mooring (June 2012 to June 2016)

(2) Nutrient (nitrate) availability

Figure S3 shows the mixed layer nitrate concentration measured by an Argo near station Papa (Monterey Bay Aquarium Research institute (MBARI) Argo Float F7601, WMO \# 5903714, http://www.mbari.org/science/upper-ocean-systems/chemical-sensor-group/floatviz/). There was no nutrient limit when the ANCP was the lowest in 2013-14. The nitrate concentration was near zero for a short period in the fall of 2015, but it went back in a short time and it didn't seem that nitrate is the limiting factor for biological production in this case.

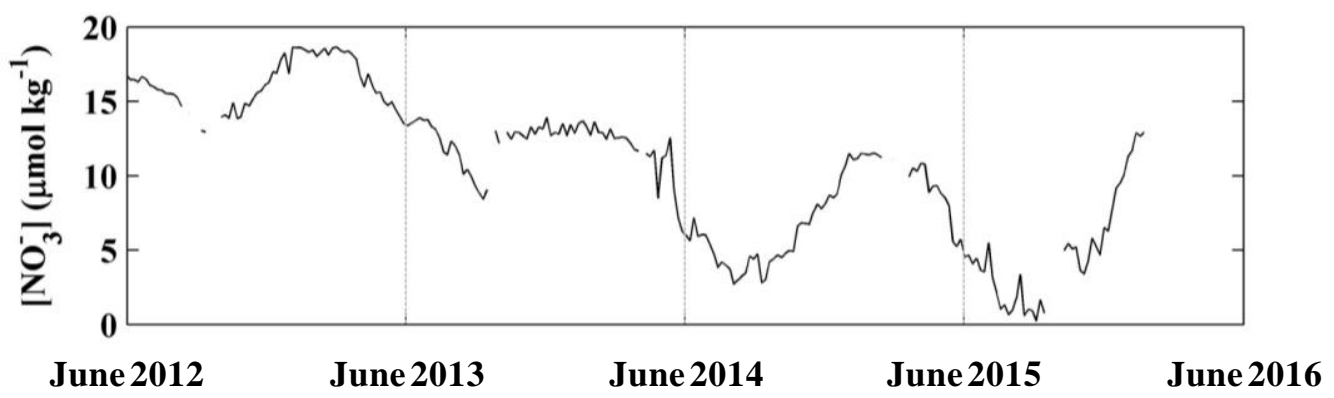

Figure S3 Nitrate data from MBARI Argo Float near Ocean Station Papa

\section{Reference}

Emerson, S., and J. Hedges. 2008. Chemical oceanography and the marine carbon cycle,. 